\title{
THE NEW ENVIRONMENT
}

\author{
C. ERIC Stroud, B.Sc., M.R.C.P., D.C.H. \\ Consultant Paediatrician, King's College Hospital, \\ London, S.E.5.
}

LONDON has for many centuries been cosmopolitan, yet until recently the number of immigrant people has been fairly small. For instance in the 1951 census the number of West Indian residents in Lambeth was only 414 . In other parts of Great Britain the number of coloured immigrant people was almost negligible. During the past decade, however, the position has altered to such an extent that over one per cent of our national population is composed of coloured immigrant people. This influx of immigrant people of different race, colour and cultures has brought with it many social and medical problems. For many big cities these problems are serious for the immigrants keep to the large cities so that in centres such as London, Birmingham and Glasgow there are very large immigrant populations. Within these cities are areas such as Brixton and Smethwick where the immigrant people tend to settle and it is in areas such as these that the problems resulting from the mass immigrations of 1956 to 1962 are becoming more and more serious.

Some of the medical problems are not primarily associated with the adaptation of the new arrivals to their new environment. Diseases such as sickle cell anaemia and thalassaemia are genetically determined and are discussed elsewhere in this journal. Apart from these haemoglobinopathies nearly all the medical problems of immigrant communities are related to environmental factors. There are many diseases and injuries to which the children of immigrant people are peculiarly liable, and it is essential that doctors working in immigrant areas should be aware not only of these conditions but also of their aetiologies, for one factor these diseases and injuries have in common is their preventability.

\section{Nutritional Deficiencies}

The first group of diseases are those related to the nutrition of immigrant children. The feeding patterns in these communities tend to be traditional and this applies particularly to infant feeding. Malnutrition as illustrated by the classical syndromes of kwashiorkor (protein malnutrition) and marasmus are for practical purposes non-existent, but two nutritional diseases have been well reported (Davis, Marten and Sarkany, 1960; Dunnigan, Paton, Hesse, McNicol, Gardner and Smith, 1962; Benson, Stroud, Mitchell and Nickolaides, 1963), namely iron deficiency anaemia and rickets.

The increased frequency of iron deficiency anaemia in immigrant children was reported by Davis and others in 1960 . They investigated 114 infants of whom 47 were West Indian and 67 were European. The weights of these children showed no statistical difference but the haemoglobin levels of the West Indian children were significantly lower at all ages from five to twenty-four months. The anaemia showed the characteristics of iron deficiency and this finding has been confirmed by others, such as Oppe in 1964. The anaemia is most marked amongst West Indian and Greek Cypriot children. The child may present with pallor or the anaemia is discovered on investigation of a child who is seen for some unrelated condition. It seems likely that the cause is related to the long initial period of breast milk, or cow's milk, feeding, for breast milk contains only $0.02-0.35 \mathrm{mg}$. per cent of iron and cow's milk only $0.2 \mathrm{mg}$. per cent. The early age at which the anaemia is discovered suggests that depleted iron stores in the mother may be an aggravating factor, but the early results of an investigation at present being carried out by Drs. Davis, Rawstron and myself show no difference in the haemoglobin and serum iron status of West Indian and English mothers. Even after weaning onto solid food many immigrant children depend largely on milk for their protein requirements, and the rest of the diet is made up with carbohydrate foods, such as rice, bread, potatoes or the more traditional green bananas and tropical vegetables, such as "cho cho". The conditions found in tropical countries which cause or aggravate the anaemia, such as hookworm infestation or malaria, are not commonly seen for the majority of the children are born in this country. 
Iron deficiency anaemia has a particular danger for the children of immigrant people for one of the common symptoms of iron deficiency is pica. This is the name given to the habitual eating of materials which are not foodstuffs, such as coal, dirt, plaster, earth and paint off woodwork and toys. This symptom clears up when the anaemia is cured but many of the children live in appalling housing conditions surrounded by old lead-containing paint and it is not surprising that many hospitals in immigrant areas have experience of lead poisoning in immigrant children. Although iron deficiency is the commonest cause of anaemia in immigrant children, care must be taken to exclude thalassaemia in Greek Cypriot children, and sickle cell anaemia in children of negro origin. This is particularly important in the case of thalassaemia for oral iron in this disease is not only useless but is contra-indicated. All children during the first two years of life on a largely milk diet should be given additional iron to prevent anaemia developing.

The other nutritional disease reported amongst children of immigrant peoples is rickets. It is tempting to ascribe the frequency of rickets to the pigmentation of the West Indian and Pakistani children, but the condition is also seen in Greek Cypriot and Irish children and has been reported by Arneil and Crosby (1963) in Scottish children in Glasgow. Like the history in the case of anaemia, the one common feature of the reported cases is that the children are fed for long periods on breast milk or cow's milk, without any supplementary vitamin administration. Cow's milk contains only 0.3 to 4.0 units Vitamin D per cent, while human breast milk varies from 0.410 units per cent. A baby who receives no supplementation is, therefore, well below the optimal levels for normal development.

Out of nineteen cases reported by Benson and others in 1963, only one child was English and he was a child of a 'problem family'. The absence of rickets in the English children of London is probably fortuitous for the majority are fed on dried milks to which Vitamin D has been added.

One of the most impressive reports of rickets in a community is that of Dunnigan, and others in 1962 who found that of seventy-four children and adults examined, thirty-five showed clinical, radiological or biochemical evidence of Vitamin $\mathrm{D}$ deficiency. Other reports are of children with clinical rickets and it is not surprising that the ages of these children fall in the first three years of life, for this is the period of most active growth and therefore clinical rickets is more likely to be evident in this age grous Dunnigan's findings suggest, however, that a survey of children by biochemical investigation would reveal Vitamin D deficiency to be verw widespread amongst the age groups.

In this field of nutritional diseases one might hope that the welfare clinic services would be effective in preventing illness but in many cases? children of immigrant mothers are not takep to Welfare Clinics. The reasons for this are often peculiar to specific racial groups. For instance the Greek Cypriot mothers are ofteg unable to speak English, even after living for a number of years in England and therefore find great difficulty in understanding instruc. tions at Welfare Clinics. In the case of West Indian mothers the problem is more complicated as the majority of the mothers care very adequately for their children and readily atten Welfare Clinics and take their advice. The problem in the West Indian communities is that many mothers go out to work during the dao and the children are sent to child-minders whe care for a number of children each day. The mothers often breast feed the babies at night and for the first morning feed, and the childeer are fed cow's milk during the day. Some soo the mothers have to work during the day $\bar{Q}$ eפ cause the wage of the unskilled father is $\overrightarrow{n o}$ sufficient to pay the high rents demanded fo accommodation and provide the essentials of life for the family. Perhaps a more commog problem is the predicament of the many single mothers who live in one room with their babs and often pay as much as $£ 35 \mathrm{~s}$. Od. per week in rent. At home in the West Indies the grandF mother would, in the traditional manner, care for the child but in London there is no grand? mother and so again the child is sent to child-minder while mother works during the day. Some of these mothers are in very difficulis financial circumstances and although some fathers make a contribution to the expenses of their illegitimate children, others do so sporadically or not at all. Attendance at hos pital or Welfare Clinics for these mothers is very difficult because of the lost wages. Thus the children who are most 'at risk' are the children who are least likely to be able tow attend Welfare Clinics.

One further point of practical importance is that many immigrant mothers dislike givinge cod liver oil to their babies, especially as it so easily taints the clothing with a persistent smell,, 0 and so even if the mother is given cod liver oi at the clinic it is often not given to the child. 


\section{Infections}

The second group of diseases to be considered are those related to infections and in this group the importance of the appalling housing conditions is very easy to appreciate. Gastro-enteritis is now common, especially in the summer months, and the children are often brought to hospital in the evening after the mother has returned from work. The close contact of children in child-minders' houses is an important factor in the spread of this disease and if breast feeding loses its popularity one must expect a large increase in gastrointestinal disease.

Tuberculosis is a very serious problem. This disease had largely been controlled in England but with the immigration of thousands of people into bad housing accommodation from countries where tuberculosis is common the problem is again becoming a serious one in certain areas. For instance, in the Paediatric Department of King's College Hospital we have admitted 11 cases of tuberculosis in the past twelve months and of these 1 was English while the others included 7 West Indian, 1 Cypriot and 2 Maltese. The difficulty in many cases is the tracing of contacts because of the tenement type of housing, coupled with a large floating population. In this respect the necessity of a chest X-ray for any immigrant wishing to settle in this country seems long overdue. Venereal disease is seen not uncommonly amongst the West Indian adults, but congenital infection is very rare because the majority of the mothers attend ante-natal clinics and are, therefore, discovered and treated before the baby is born.

One rather interesting but very serious problem, reported by Parsons in 1963, is the high incidence of Rubella Syndrome. The mother from the West Indies must come from an area where rubella is not common in the way it is in England and so when a local epidemic occurs in an immigrant area many pregnant women are affected. Professor Parsons reported 25 cases while we have in two years seen seven cases, of which six were in West Indian babies.

\section{Other Problems}

Perhaps more important than these nutritional and infective disorders are the difficulties found by immigrant children directly related to their environment. In particular the danger from burns needs to be stressed. In the burns units of a number of hospitals in London, immigrant children often comprise up to $40 \%$ of the cases admitted. In any winter a number of coloured immigrant children will be burnt to death and the cause of these deaths can be traced directly to the housing conditions. Most immigrant peoples come from countries where the most popular fuel for cooking and heating is paraffin. In this country they find themselves living in one or two rooms in a large house. The house itself is very often occupied by three or four families and the landlord carries out a minimum of repairs and provides a minimum of facilities. It is very unusual for the single rooms to have meters installed and the landlord often forbids the use of gas or electric fires. As a result paraffin oil heaters are the most common form of heating used during the winter. In a survey I carried out on over 100 families, $95 \%$ used paraffin heaters. The housing situation is such that many mothers share one kitchen and the bathroom and lavatory is also shared. Many oil heater fires occur as a result of children playing in a room in which an oil heater is burning while the mother is in the kitchen, or even out of the house. The number of oil heater fires in London rose from 934 in 1957 to 1,684 in 1959 (Leete, 1963) and this rise coincided with the inflow of immigrants to this country. Apart from burns the widespread use of oil heaters has resulted in another hazard for the children-namelye paraffin poisoning. The paraffin is usually kepto in a bottle and many West Indian children are? admitted to hospital after drinking paraffin. Many of these children are very ill with pneumonia-a common complication.

Some conditions which particularly affect immigrant children are not easily explained and the biggest medical mystery is infantile eczema. Although figures are not available there is no doubt in the minds of those dermatologists who work in immigrant, and especially West Indian, areas that infantile eczema is much more common than in English children. Aetiological factors are hard to find and it seems that the introduction of a large number of children to an environment of which their preceding generations have had no experience is the basic cause of this phenomenon. These children with eczema have very high eosinophil counts but there is also the phenomenon of many West Indian children with unexplained high eosinophil counts who are not particularly ill. These children do not have any helminth infestation and the majority of them have not been out of this country.

We have so far discussed organic disease but perhaps the most important aspect of the health of immigrant children is the emotional stresses on the child as a result of the difficulties 
which face some immigrant families. The high proportion of mothers who are unmarried leads to a great deal of mother-child separation in the early years of life and later on the child has to attend school where most of the other children have fathers. In addition there is very often quite severe financial difficulty for a single mother earning $£ 9$ per week may quite well be paying out $£ 610 \mathrm{~s}$ 0d. in rent, fuel, travelling expenses and tax, leaving very little for food and clothing. Child guidance clinics in immigrant areas are seeing an increasing number of coloured children who show early evidence of emotional disturbance. One interesting problem which we have seen particularly in West Indian children is mutism in children who are neither deaf nor mentally retarded. A new problem now seems to be occurring. Many mothers came over to this country five or six years ago and left their children, in the accepted traditional manner, with the grandmother. Some of these mothers can now afford to pay for their children to travel to this country and live with them again. This is a very stressful situation for a child who has forgotten the mother and has grown to love the grandmother who is for practical purposes the mother. Very often the mother is now living with or married to another man and has new children who suddenly have to be accepted as brothers and sisters. It is not surprising, therefore, that we see in these immigrant children symptoms attributed to these disturbances-bedwetting, anorexia, mutism and, particularly, behaviour disorders are all common. What is more important is what will happen to these children as they grow up. The disturbed child is more likely to become deliquent than the well-adjusted child and there are many potentially delinquent children who at present are reacting to their environment by being emotionally disturbed.

The future of the single mother is also one which should cause us a great deal of concern for in thirty years' time she will be an old, single lady unable to work and unable to pay for her accommodation and care. If she becomes ill there will in many cases be no-one to look after her and hers will be one of the most serious components of a future geriatric problem which is a grave one even when only the indigenous population is considered.
Preventive measures in this wide field of disease are difficult. The basis, as in all pre ventive health problems, is health education The difficulty is that the family most at ris is the family most difficult to reach. Welfare Clinics are held at the wrong time. There are few places where immigrant people gather to gether so that some form of health educatio can be given. One possibility is that everg maternity unit should have attached to it $\approx$ health educator who should preferably be of the same origins as the immigrant people who attend the unit. It would be important that the health education should be directed at af mothers, not just the immigrants. Many ine migrant mothers have too many children yeet one finds that there is no attempt at any fornt of birth control. Family planning should be कo very important part of the education of the mothers and fathers. The biggest problem is without doubt the problem of housing. Indigen ous families in big cities also have, in many cases, appalling housing conditions and wide spread rehousing programmes for immigranc peoples would very likely cause resentment. lot could be done, however, in the control of present tenancy conditions.

As new generations of immigrants appears some of the problems related to the separation from "home" will disappear but if we accepp the situation as it is and interest ourselves only in the cure of the individual organic dis? eases new problems will arise and the future will be even more difficult than the present.

\section{REFERENCES}

Arneil, G. C., and Crosby, J. C. (1963): Infantile Rickets Returns to Glasgow, Lancet, ii, 423.

Benson, P. F., Stroud, C. E., Mitchell, N., and. NiCKOLIADES, A., 1963: Rickets in Immigranश Children in London, Brit. med. J., 1054.

Davis, L. R., MARTEN, R. H., and SARKANY, I. (1960) Iron Deficient Anaemia in European and Wes? Indian Infants in London, Brit. med. J., ii, 1426.

Dunnigan, M. G., Paton, J. P., Hasse, S., McNicolo G. W., Gardner, M. D., and SMITH, C. M? (1962: Late Rickets and Osteomalacia in the Pakistani Community in Glasgow, Scot. med. $J . \frac{7}{2}$
7, 159 .

Leete, L. W. T. (1963): London Fire Brigade. Per sonal communication.

PARsons, C. G. (1963): West Indian babies with Multiple Congenital Defects, Arch. Dis. Child., 380 38,454 .

Oppe, T. (1964): Medical Problems of Coloured Immigrant Children in Britain, Proy. roy. Soc. Med 57, 321 . 